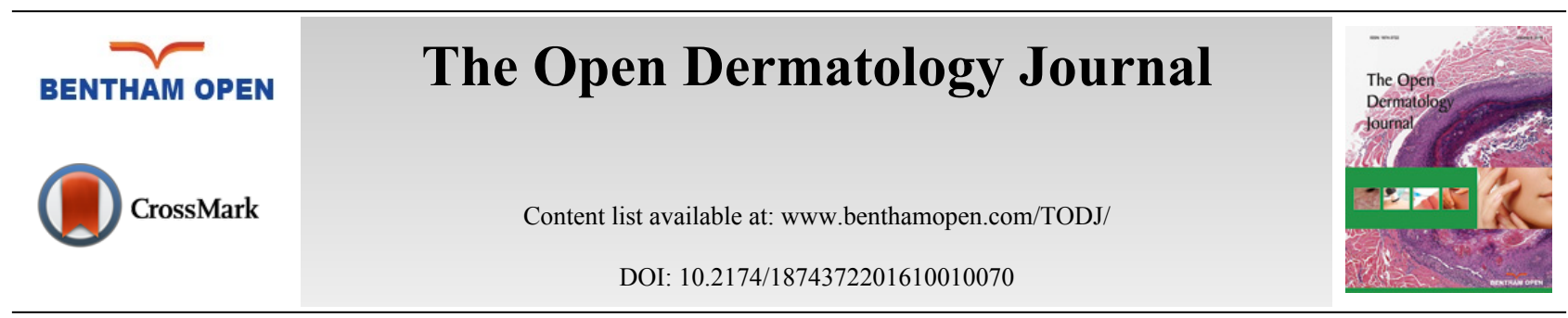

\title{
Therapy of Lyme Disease
}

\author{
Giusto Trevisan ${ }^{1, *}$, Enzo Errichetti ${ }^{2}$, Nicola di Meo ${ }^{1}$, Caterina Pinzani ${ }^{2}$, Katiuscia Nan $^{2}$ and Giuseppe \\ Stinco $^{2}$ \\ ${ }^{I}$ Dermatology and Venereology Department, University of Trieste, Italy \\ ${ }^{2}$ Department of Experimental and Clinical Medicine, Institute of Dermatology, University of Udine, Italy
}

\begin{abstract}
Borrelia burgdorferi is highly susceptible to antibiotic treatment and the majority of patients profit from this treatment. Antibiotic selection, dose and route of administration, and duration of therapy for Lyme disease depend on the patient's clinical manifestations and stage of disease, age, pregnancy status, as well as the presence of other concomitant diseases and/or allergies. Despite an appropriate antibiotic therapy, about $10-20 \%$ of patients may show persistent or recurrent symptoms ("post-treatment Lyme disease syndrome").

In the present paper we will briefly discuss the post-exposure prophylaxis, before going on to talk over the current therapeutic approach regarding the management of Lyme disease according to the stage of disease/clinical manifestations. Finally, we will discuss the main treatment-related phenomenon, the Jarisch-Herxheimer reaction, and the treatment modalities for special categories of patients, namely pregnant women, subjects suffering from post-treatment Lyme disease syndrome, possible Borrelia-associated skin manifestations, coinfections and Baggio-Yoshinary syndrome.
\end{abstract}

Keywords: Borreliosis, Baggio-Yoshinary syndrome, Jarisch-Herxheimer reaction, Lyme disease, Therapy, Treatment.

\section{INTRODUCTION}

Lyme disease (LD) is a tick-transmitted multisystem inflammatory disease caused by the spirochete Borrelia burgdorferi sensu lato [1 - 4]. In particular three genospecies have been considered important human pathogens, Borrelia burgdorferi sensu stricto in the USA and Europe, and Borrelia afzelii and Borrelia garinii in Europe and Asia $[5,6]$. Potential pathogenic Borrelia species include Borrelia bavariensis, Borrelia bissettii, B. kurtenbachii, Borrelia Spielmanii, Borrelia lusitaniae, and Borrelia valaisiana [7]. The pathogenic Borrelia miyamotoi was identified in Japan [8], and is now known to be present in the USA and Russia [9], and recently discovered in the UK [10]. Borrelia burgdorferi is highly susceptible to antibiotic treatment and the majority of patients profit from this treatment. Antibiotic selection, dose and route of administration, and duration of therapy for LD depend on the patient's clinical manifestations and stage of disease, age, pregnancy status, as well as the presence of other concomitant diseases and/or allergies [11, 12]. Importantly, about $10-20 \%$ of patients (especially those who are diagnosed later), following appropriate antibiotic treatment, may have persistent or recurrent symptoms and are considered to have "post-treatment Lyme disease syndrome" [13]. In some cases, other microorganisms may be cotransmitted through the tick bite [8, 12 , 14]. Patients found to have coinfections should be treated with appropriate therapies.

In the present paper we will briefly discuss the post-exposure prophylaxis, before going on to talk over the current therapeutic approach regarding the management of LD according to the stage of disease/clinical manifestations. Finally, we will discuss on the main treatment-related phenomenon, the Jarisch-Herxheimer reaction, and the treatment modalities for special categories of patients, namely pregnant women, subjects suffering from post-treatment Lyme disease syndrome, possible Borrelia-associated skin manifestations, coinfections and Baggio-Yoshinary syndrome.

\footnotetext{
* Address correspondence to this author at the Clinica Dermatologica, Università degli Studi di Trieste, IV piano Palazzina Infettivi-34100 Trieste, Italy; Tel: +390403992056; Email: trevisan@units.it
} 


\section{POST-EXPOSURE PROPHYLAXIS}

Chemoprophylaxis of LD after a tick bite has been the subject of debate in recent years. In the unique randomized, double blind, placebo-controlled trial conducted, effective chemoprophylaxis was achieved using a single dose of 200 $\mathrm{mg}$ oral doxycycline within 72 hours of removal of Ixodes scapularis ticks [15]. The last guidelines from the Infectious Diseases Society of America, recommend offering doxycycline prophylaxis to patients in the United States with known Ixodes scapularis attachment of at least 36 hours within 72 hours of tick removal. This recommendation is only applicable in areas endemic to Borrelia burgdorferi sensu lato, where tick infection rates are at least 20\% [11, 14]. Prophylactic antibiotic therapy may not be suitable for patients with bites from ticks other than Ixodes scapularis; furthermore, it is not currently recommended for those attacked by Ixodes ricinus in Europe [14].

Post-exposure prophylaxis is not without risks; indeed, insufficient prophylaxis may increase the potential for insidious progression of disease in the absence of seroconversion, and some authors speculate that inadequate antibiotic therapy in the setting of prophylaxis may promote the development of antibiotic-resistant organisms. However, there are currently no data showing acquired antibiotic resistance to be the cause of treatment-refractory LD or post-treatment Lyme disease syndrome [14].

\section{EARLY LOCALIZED DISEASE (ERYTHEMA MIGRANS \pm NONSPECIFIC CONSTITUTIONAL SYMPTOMS)}

The management options for such stage of disease are represented by oral antimicrobial therapies, including doxycycline (200 mg/day, divided into two doses daily; pediatric dose: $4 \mathrm{mg} / \mathrm{kg} / \mathrm{day}$ ), amoxicillin (1500 mg/day, divided into three doses daily; pediatric dose: $50 \mathrm{mg} / \mathrm{kg} /$ day), or cefuroxime axetil (1 g/day, divided into two doses daily; pediatric dose: $30 \mathrm{mg} / \mathrm{kg} /$ day) [12]. While ten days of therapy (range 10-21 days) are generally sufficient for doxycycline, a longer administration (at least 14 days; range 14-21 days) is required for amoxicillin or cefuroxime axetil, given the much shorter half-life of such $\beta$-lactam drugs. Therefore, for uniformity, a 14-day course of therapy is advised for all of the first-line oral agents [11]. Doxycycline is generally preferred since it has the advantage of being also effective for treatment of human granulocytic anaplasmosis and Borrelia lonestari and Borrelia miyamotoi infections (but not for babesiosis), which may occur simultaneously with early LD; however, it is contraindicated in children $<8$ years of age and during pregnancy or lactation $[11,14,16]$. Cefuroxime axetil is usually considered as a second-line treatment because of its cost [14]. Two small studies found that doxycycline (100 mg twice-daily) and amoxicillin (500 mg three times a day, plus probenecid at the same dose), both administered for ten days in one study and for three weeks in another, had a comparable efficacy in the treatment of early localized LD [17, 18]. Two other studies on the treatment of erythema migrans compared cefuroxime axetil (500 mg twice per day for 20 days) with doxycycline (100 mg 3 times per day for 20 days), demonstrating similar efficacy [19, 20]. In a separate randomized trial of 43 children with erythema migrans, 2 different dosage regimens of cefuroxime axetil ( $20 \mathrm{mg} / \mathrm{kg}$ per day or 30 $\mathrm{mg} / \mathrm{kg}$ per day) were found to have efficacy comparable to amoxicillin (50 mg/kg per day) [21]. Patients who are intolerant/allergic to amoxicillin, doxycycline, and cefuroxime axetil may be alternatively treated with macrolide antibiotics (azithromycin at the dose of $500 \mathrm{mg}$ orally per day (pediatric dose: $10 \mathrm{mg} / \mathrm{kg}$ per day with a maximum of $500 \mathrm{mg}$ per day) for 7-10 days, clarithromycin at the dose of $500 \mathrm{mg}$ orally twice per day (pediatric dose: $7.5 \mathrm{mg} / \mathrm{kg}$ twice per day with a maximum of $500 \mathrm{mg}$ per dose) for 14-21 days, or erythromycin at the dose of $500 \mathrm{mg}$ orally 4 times per day (pediatric dose: $12.5 \mathrm{mg} / \mathrm{kg} 4$ times per day with a maximum of $500 \mathrm{mg}$ per dose) for 14-21 days) [11]. Such drugs are not recommended as first-line therapy for early LD since they are less effective, with cure rates of about $80 \%$ (12). A multicenter, double-blind, randomized, prospective trial comparing amoxicillin (500 mg 3 times per day for 20 days) with azithromycin (500 mg once per day for 7 days) for the treatment of patients with erythema migrans found that the former was significantly more effective than azithromycin for complete resolution of the acute manifestations of erythema migrans and for prevention of relapse in a 6-month period; of 217 evaluable subjects, only $4 \%$ of those treated with amoxicillin experienced relapse, compared with $16 \%$ of those treated with azithromycin [22]. Therefore, patients treated with macrolides should be closely observed to ensure resolution of the clinical manifestations. In contrast to the second-generation cephalosporin cefuroxime and the third-generation cephalosporins ceftriaxone, first-generation cephalosporins, such as cephalexin, are inactive in vitro against Borrelia burgdorferi and are ineffective clinically. Importantly, ceftriaxone, while effective, is not superior to oral agents and is more likely than the recommended orally administered antimicrobials to cause serious adverse effects. Therefore, ceftriaxone is not recommended for treatment of patients with early localized LD [11]. 


\section{EARLY DISSEMINATED DISEASE}

\subsection{Early Neuroborreliosis (Meningitis and Other Neurological Manifestations Lasting Less Than 6 Months)}

According to the most recent recommendations on this topic [23], such a group of patients should be treated with a single 14-day (range 10-28 days) course of antibiotic therapy. In most European studies, the duration of treatment ranged from 10 to 14 days, while only in few studies it was extended to 28 days. Interestingly, the occurrence of persistent residual symptoms after standard antibiotic therapy in some cases has led to speculations about surviving bacteria and an eventual need for longer treatment duration, but there are no high quality data supporting a similar assumption.

Patients with peripheral nervous system involvement (meninges, nerve roots, cranial and/or peripheral nerves) may be treated with both oral doxycycline $(200 \mathrm{mg} /$ day, divided into two doses daily; pediatric dose: $4 \mathrm{mg} / \mathrm{kg})$ and intravenous therapies, including ceftriaxone ( $2 \mathrm{~g}$ single daily dose; pediatric dose: $50-75 \mathrm{mg} / \mathrm{kg}$ with a maximum of 2 g), penicillin G (generally 20 million U daily, divided into six doses every four hours, with a possible range of 18-24 million U/day; pediatric dose: 200-400 thousands U/kg/day, not exceeding 24 million $\mathrm{U}$ a day) or cefotaxime (3 g two times daily or $2 \mathrm{~g}$ three times daily; pediatric dose: $200 \mathrm{mg} / \mathrm{kg} / \mathrm{die}$, divided in 3 doses daily, with a maximum of 6 g/day) [24, 25 - 27]. According to some studies, the three intravenous regimens present a similar efficacy [26, 27] and doxycycline and intravenous ceftriaxone for 14 days are equally effective [28 - 31]. At the moment, there is no significant data suggesting the use of intravenous drugs over oral doxycycline (which is easier to administer and cheaper) [23].

Pediatric population should be treated with the same drug options and timing of the adults [23], although a Swedish study involving 203 children with early neuroborreliosis has reported good results with shorter therapies (10 days) based on intravenous beta-lactam antibiotics or oral doxycycline (contraindicated in children less than 8 years) [32].

Regarding patients with central nervous system involvement (encephalitis, myelitis), the only recommended therapy is represented by intravenous ceftriaxone ( $2 \mathrm{~g}$ daily; pediatric dose: $50-75 \mathrm{mg} / \mathrm{kg}$ with a maximum of 2 per day) for 14 days [23]. Interestingly, a Swedish Slovenian study comparing intravenous ceftriaxone and oral doxycycline in the treatment of encephalitis has reported a good and comparable improvement in both groups of patients [29].

\subsection{Myopericarditis and Atrioventricular Heart Blocks}

Generally, for symptomatic patients (e.g. presenting syncope, dyspnea, or chest pain) and/or subjects with secondor third-degree atrioventricular block or first-degree heart block with PR interval prolonged to 300 milliseconds, the hospitalization with continuous monitoring is advised [33]. The management options for treating myopericarditis and atrioventricular heart blocks include both oral and parenteral antibiotic therapy for 14 days (range 10-28 days) [11]. In particular, hospitalized patients are treated with intravenously antibiotics, such as ceftriaxone (at the single dose of $2 \mathrm{~g}$ daily; pediatric dose: $50-75 \mathrm{mg} / \mathrm{kg}$ per day with a maximum of $2 \mathrm{~g}$ daily) [11], cefotaxime (6 g divided into 3 doses/daily; pediatric dose: $150-200 \mathrm{mg} / \mathrm{kg} /$ day with a maximum of $6 \mathrm{~g}$ per day) [12] or penicillin $\mathrm{G}$ ( $0.5 \mathrm{million}$ $\mathrm{U} / \mathrm{kg} /$ day, divided in four-six doses daily, with a maximum of $20 \mathrm{million} \mathrm{U} /$ day) [24], albeit there are no relevant clinical trials to support these therapeutic approaches. In case of advanced heart block, a temporary pacemaker may be required (at least since the advanced heart block has been resolved) [34, 35]. The oral antibiotic treatment represents the first choice for outpatients, with the same regimen used for manifestations of erythema migrans without carditis (see above) [12]. In the literature, there is no high-quality evidence to suggest that parenteral antibiotic therapy is more effective than oral antibiotic therapy in the treatment of Lyme-associated cardiac manifestations and that antibiotic therapy in general acts on them. Anyhow, antibiotic therapy is currently recommended in order to block the progression of the cardiac involvement in patients with LD [34].

\subsection{Skin Manifestations (Borrelial Lymphocytoma and Multiple Erythema Migrans)}

Borrelial lymphocytoma may be treated with the same regimens used for erythema migrans (see above), but there are no relevant clinical trials showing which is the best therapeutic approach $[11,12]$. According to one study involving 65 patients with borrelial lymphocytoma of the ear lobe or of the breast, the effectiveness of oral doxycycline, azithromycin and amoxicillin (administered at the same dosage than for single erythema migrans) is comparable [36]. However, the number of patients in these study is too low and pretreatment characteristics are too heterogeneous for a reliable comparison of the efficacy of different antibiotics, consequently the optimal agent, dosage and duration of therapy for borrelial lymphocytoma cannot be determined [11]. Importantly, the choice of treatment duration should 
take into account that the disappearance of the lymphocytoma takes longer in patients with prolonged duration prior to treatment [36, 37].

According to the European Concerted Action on Lyme Borreliosis, multiple erythema migrans are usually treated with intravenous ceftriaxone for 3 weeks (at the single dose of $2 \mathrm{~g}$ daily; pediatric dose: $50-75 \mathrm{mg} / \mathrm{kg}$ per day with a maximum of $2 \mathrm{~g}$ daily), oral amoxicillin for $14-30$ days $(1500 \mathrm{mg} /$ day divided in 3 doses daily; pediatric dose: 50 $\mathrm{mg} / \mathrm{kg}$ /day) or doxycycline for 14-30 days (100-150 mg in 2 doses/day) [38]. A Finnish study involving 16 patients with multiple erythema migrans, showed a cure rate of $100 \%$ (4/4 patients), $80 \%$ (4/5 patients, with one only partially healed) and $86 \%$ (6/7) for amoxicillin, doxycycline and ceftriaxone, respectively [39]. One larger randomized controlled trial on 140 patients with early disseminated LD ( most of them presenting multiple erythema migrans) treated either for 14 days with ceftriaxone or for 21 days with doxycycline showed no significant differences in cure rates between the two groups [26].

\section{LATE DISEASE}

\subsection{Arthritis}

Patients suffering from arthritis without evidence of neurological involvement can usually be treated successfully with oral antibiotics for 28 days. In particular, doxycycline, amoxicillin or cefuroxime axetil are currently used at the same adult or pediatric dosage of early localized disease (see above) [11]. The concomitant use of probenecid with amoxicillin is not advised since probenecid may impair the penetration of beta-lactam antibiotics into brain parenchyma $[40,41]$. A cost-effective analysis has shown that for most patients with Lyme arthritis, intravenous therapy appears to be no more effective than oral therapy, is more likely to result in serious complications, and is substantially more expensive, thus supporting that oral antibiotics should be considered as the first therapy for Lyme arthritis in the absence of concomitant neurologic involvement [42]. However, it is important to underline that a small number of patients treated with oral agents may subsequently manifest overt neuroborreliosis, requiring intravenous therapy with a beta-lactam antibiotic for resolution [11].

Patients with arthritis plus objective evidence of neurological disease should receive parenteral therapy with ceftriaxone (at the single dose of $2 \mathrm{~g}$ daily; pediatric dose: $50-75 \mathrm{mg} / \mathrm{kg}$ per day with a maximum of $2 \mathrm{~g}$ daily) or, in alternative, cefotaxime or penicillin $\mathrm{G}$ at their standard dosage (see above) for 2-4 weeks [11, 43, 44]. According to some studies, in most cases 2 weeks of intravenous therapy with ceftriaxone is enough for resolving the illness [45, 46]. Compared with penicillin, the advantages of ceftriaxone are its excellent cerebro-spinal fluid penetration and long serum half-life, which permits once-per-day dosing. However, ceftriaxone may cause biliary complications, which are not reported with cefotaxime administration [44].

Generally, in cases of arthritis not completely resolved after a recommended course of oral antibiotic therapy, another 4 week-course of oral antibiotics is advised. While, in case of complete lack of response (or worsening) after adequate therapy, patients are more suitable to undergo 2-4 week-course of intravenous ceftriaxone [11]. For inpatients, some Authors suggested the use of intravenous cefotaxime (three divided doses) because of the lesser incidence of biliary side-effects. Anyhow, clinicians should wait several months before initiating re-treatment with antibiotics due to the possible slow resolution of inflammation after treatment. During this period, non steroidal anti-inflammatory drugs may be used [47], while intra-articular injections of corticosteroids are not recommended [11]. For patients with negative PCR results of synovial fluid, in whom joint swelling is persistent or recurrent even after the retreatment, only symptomatic therapies are recommended, including non steroidal anti-inflammatory drugs, intra-articular injections of corticosteroids, hydroxychloroquine, and/or also arthroscopic synovectomy to reduce the swelling (if persistent synovitis is associated with significant pain or limitation of function) [48]. A study on 20 patients who underwent the latter procedure for refractory chronic Lyme arthritis of the knee showed that 16 cases (80\%) had resolution of joint inflammation within the first month or soon thereafter [49]. Immunological features, genetic factors and pathogenrelated factors might all contribute to the evolution into a rheumatoid-like disease. Even though a significant portion of treatment-refractory patients with Lyme arthritis has been noted in several studies, the general consensus is that antibiotic treatment remains the cornerstone of therapy [24].

\subsection{Late Neuroborreliosis (Peripheral and Central Neurological Manifestations Lasting More Than 6 Months)}

Adult patients with symptoms confined to the peripheral nervous system should be treated with oral doxycycline (200 mg daily, divided into two doses per day) or intravenous ceftriaxone ( $2 \mathrm{~g}$ once a day) for 3 weeks (range $2-4$ 
weeks) [23]. According to some authors, intravenous penicillin (20 million $U$ daily for 10 days) is a possible parenteral alternative to ceftriaxone $[23,27,50]$. Albeit there is no high quality evidence, the outcomes of the oral and the intravenous therapeutic strategy seem to be comparable. Indeed, a Swedish study on over 40 patients suffering from acrodermatitis chronica atrophicans and late neuroborreliosis with peripheral involvement showed a similar response rate on neurological manifestations between a group (21 patients) receiving oral doxycycline for 3 weeks and a group (21 patients) receiving intravenous penicillin for 2 weeks followed by oral doxycycline for other 2 weeks [50]. Similarly, another analysis of 10 patients with late neuroborreliosis with peripheral involvement showed equal improvement after 14 days of oral doxycycline as after 14 days of intravenous ceftriaxone [31]. Adult patients with neuroborreliosis involving the central nervous system (myelitis, encephalitis, vasculitis) should be treated with intravenous ceftriaxone ( $2 \mathrm{~g}$ daily, once a day) for 3 weeks [23]. An European open-label study of late neuroborreliosis (defined as non-specific central nervous system symptoms, without cerebrospinal fluid pleocytosis or other neurological findings) showed similar improvement rates ( $59 \%$ vs $67 \%$ respectively) six months after treatment with four weeks of oral doxycycline versus two weeks of intravenous ceftriaxone followed by two weeks of oral doxycycline [51].

There are not enough data to support the use of steroids alone or in combination with antibiotics in neuroborreliosis [23].

\subsection{Ocular Manifestations (Keratitis, Uveitis)}

There are no high quality recommendations on such manifestations of LD because of the lack of evaluable data on ophthalmologic complications, which are very rare [11]. Anyway, the best approach for these patients might be a trial of intravenous antibiotic therapy (ceftriaxone at the dose of $50 \mathrm{mg} / \mathrm{kg} /$ day for $2-3$ weeks). If patients respond to treatment, ocular LD is diagnosed, and no other therapy is needed [52, 53]. Other authors suggest the use of doxycycline for 28 days $(4 \mathrm{mg} / \mathrm{kg} /$ day in two divided doses, with a maximum of $200 \mathrm{mg} / \mathrm{day}$; after 8 years of age) [24]. In cases of recurrences of ocular manifestations, once adequate intravenous therapy has been given, some authors advise a judicious course of topical or systemic corticosteroids $[52,54]$. Anyhow, they should not be used in patients in whom an adequate antibiotic therapy has not been performed [52 - 54].

\subsection{Acrodermatitis Chronica Atrophicans}

According to the European Concerted Action on Lyme Borreliosis, acrodermatitis chronica atrophicans may be treated with oral drugs, including amoxicillin ( 3 x 500-1000 mg/day; pediatric dose: $25-50 \mathrm{mg} / \mathrm{kg} /$ day) and doxycycline ( $2 \times 100 \mathrm{mg} /$ day; contraindicated in children less than 8 years), or intravenous ceftriaxone ( $2 \mathrm{~g} /$ day; pediatric dose: $50-100 \mathrm{mg} / \mathrm{kg} /$ day). The treatment duration for all three drugs is 21 days (range 14-30 days) (38). An alternative therapy advised by some authors is intravenous cefotaxime $50 \mathrm{mg} / \mathrm{kg}$ /day in one dose (maximum dose 2,000 $\mathrm{mg} / \mathrm{day}$ ) for at least 4 weeks [55]. Importantly, high quality controlled studies comparing oral and parenteral antibiotic for the treatment of acrodermatitis chronica atrophicans are missing [11].

\section{JARISCH-HERXHEIMER REACTION AND THERAPEUTIC APPROACH REGARDING SPECIAL CATEGORIES/OTHER POSSIBLE BORRELIA-RELATED MANIFESTATIONS}

\subsection{Jarisch-Herxheimer Reaction}

The Jarisch-Herxheimer reaction is a treatment-related transient immunological phenomenon. It is due to the increase in circulating toxins and/or inflammatory cytokines associated with the lysis of the spirochetes, induced by the antimicrobial treatment. Clinically, it consists in short-term constitutional symptoms, including fever, chills, headache, myalgia, arthralgia, besides exacerbation of existing cutaneous lesions. This reaction occurs within 24 hours after the start of any recommended antimicrobial agent and it resolves without serious consequences within 24 hours, with no evidence of recurrence and any relationship with the outcome of the current treatment [11]. There is no conformity about incidence data of this phenomenon in relation to different spirochetes and to different therapeutic or prophylactic strategies of LD, however, an increase in the incidence may be expected among patients co-infected with HIV and other infectious diseases including syphilis [56].

\subsection{Pregnant Women}

Pregnant (and lactating) patients may be treated identically to non pregnant patients with the same disease manifestation, except that doxycycline should be avoided [11]. Interestingly, some American practitioners prescribe a 10-14-day course of prophylactic amoxicillin for pregnant women after Ixodes scapularis tick bites, since case reports 
have suggested that LD during pregnancy may be associated with adverse outcomes for the fetus [57 - 59]. However, a large amount of data from clinical and epidemiological studies suggest that there are no fetal risks when a pregnant woman with LD is treated with adequate antibiotic therapy [60 - 62]. An example is a Slovenian prospective study of 58 consecutively enrolled pregnant women with typical erythema migrans: 13 patients (22.4\%) acquired borrelial infection in the first trimester of pregnancy, $26(46.6 \%)$ in the second trimester, and $18(31 \%)$ in the third trimester. All patients were treated for 14 days: $2(3.4 \%)$ with phenoxymethylpenicillin ( 1 million IU thrice per day), 3 (5.2\%) with benzylpenicillin (10 million units twice per day), and 53 (91.4\%) with ceftriaxone ( $2 \mathrm{~g}$ daily). In most cases (51/58 women; 87.9\%), the pregnancy was normal and the infants (all born at term) were clinically healthy. Of the remaining 7 pregnancies, 1 child born at term was found to have urologic abnormalities at 7 months of age, 1 ended with a missed abortion and 5 with preterm birth ( 1 of the preterm babies had heart abnormalities). However, a causal relationship between borrelial infection and fetal adverse effects has not been proven [60].

\subsection{Post-Treatment Lyme Disease Syndrome}

About 10 to $20 \%$ of patients treated for LD with an appropriate 2-4 week course of antibiotics may experience lingering symptoms similar to fibromyalgia (e.g., fatigue, pain, joint and muscle aches) or, more rarely, they may present other manifestations such as cognitive complaints, radicular pain, paresthesias or dysesthesias [11]. Albeit often known as "chronic LD", this condition is defined as post-treatment LD syndrome (PTLDS) [63] ; it may last for weeks, months, or longer $[11,12]$. Importantly, some authors recognize two clinical pictures, namely "post-Lyme disease symptoms" if manifestations persist for less than 6 months and "post-Lyme disease syndrome" if they are disabling and persist for 6 months or longer [64]. The exact cause of PTLDS is not yet known, but most medical experts believe that it is the result of residual damage to tissues and the immune system that occurred during the infection. In contrast, other authors think that these symptoms reflect persistent infection with Borrelia burgdorferi $[23,65,66]$. Hypothetically, the persistence of Borrelia is attributed to its residency within the cell and to the development of biologically less active permanent forms (sphaeroplasts, encystment). Furthermore, Borrelia was also shown to develop biofilms with the effect of resisting complement and typical shedding (casting off antibodies from the surface of the bacterium). Other mechanisms, including changing protein antigens located on the membrane, the loss of plasmids and processes to inactivate complement, might also led the pathogen to evade the immune system [66]. Anyhow, further study are needed to clarify such open questions [63]. PTLDS has not been shown in any controlled trials to be responsive to antibiotic therapy [67]. For example, a relatively recent study failed to show a benefit of treatment with $2 \mathrm{~g}$ of intravenous ceftriaxone daily for 30 days, followed by oral doxycycline at $200 \mathrm{mg} / \mathrm{d}$ for 60 days [68]. Thus, at the moment, antibiotic therapy is not recommended for patients with PTLDS after adequate treatment regimens for LD, while symptomatic treatments may be administered to control the symptoms [11]. However, according to some authors, the use of hydroxychloroquine or metronidazole, in combination with standard antibiotics, may help in resistant chronic cases since such drugs have an effect on encysted forms [68]. Anyhow, no high quality evidence supports a similar approach.

\subsection{Controversial Skin Manifestations}

The role of $B b$ in sclerotic or degenerative conditions of the skin other than acrodermatitis chronica atrophicans remains unclear. For morphea, lichen sclerosus and athrophicus and anetodermia [69 - 73] a possible $B b$ etiology was repeatedly suggested on the basis of clinical, serological, immunohistochemical, molecular biology and culture, but for other frameworks such as granuloma annulare, pityriasis rosea, pityriasis lichenoides, erythema nodosum, papular acrodermatitis of Giannotti Crosti, Raynaud's syndrome, sarcoidosis, Reiter's syndrome, idiopathic nodular panniculitis (Pfeifer-Weber-Christian disease) and some lymphomas [74 - 80] reports are occasional and therefore require further confirmation. However both in anecdotal cases and in case series one of the validation criteria of the association was the improvement after antibiotic therapy [80]. Oral drugs, including amoxicillin (3 x 500-1000 mg/day) and doxycycline (2 x $100 \mathrm{mg} /$ day), or intravenous ceftriaxone ( $2 \mathrm{~g} /$ day), usually for 2-3 weeks (albeit longer treatment have been reported), have been used alone or in association with the typical drugs for the different diseases [69 - 82]. Naturally, since there are no certainties about the above mentioned associations there are no well-defined therapies [82].

\subsection{Coinfections}

Therapeutic resistance can be related to coinfections, that should be considered in patients who present with more severe initial symptoms in comparison to those commonly observed in LD alone and especially in patients who have high-grade fever despite receiving an appropriate antibiotic therapy for LD $[11,55]$. When patients have leucopenia and 
neutropenia after the treatment, the suspect is a coinfection by Anaplasma phagocytiphilum infection, that is transmitted by the tick Ixodes ricinus, the same vector of Borrelia. A. phagocytophilum, the causative agent of human granulocytic anaplasmosis, is a rickettsial organism that produces an acute febrile systemic illness, constitutional symptoms, and laboratory abnormalities such as leukopenia, thrombocytopenia, and elevated levels of hepatic transaminases [83]. Doxycycline is recommended as the treatment of choice for patients who are suspected of having symptomatic human granulocytic anaplasmosis. The dosage regimen for adults is $\mathbf{1 0 0} \mathbf{~ m g}$ orally twice daily for $\mathbf{1 0}$ days [55, 84]. Babesiosis is a malaria-like protozoan infection of erythrocytes that is transmitted by Ixodes spp. ticks [83, 85, 86]. It may also be acquired from blood transfusions. Several species of Babesia are capable of causing human disease; the most important of these are B. microti in the US and B. divergens in Europe. Clinical babesiosis is similar to malaria, with an onset of high fever $\left(40^{\circ} \mathrm{C}\right)$, malaise, myalgia, fatigue and anemia. Also a hepatosplenomegaly can be present [87]. Hemolytic anemia can last from a few days to a few months in severe cases, which tend to occur more frequently in the elderly and in splenectomized. The infestation with Babesia microti results milder, self-limited and possibly treatable so unspecific. The combination of either atovaquone (750 mg orally twice a day) plus azithromycin (500-1000 $\mathrm{mg}$ on day 1 and $250 \mathrm{mg}$ orally once per day thereafter) or clindamycin (300-600 mg every 6 hours intravenously or $600 \mathrm{mg}$ every 8 hours orally) plus quinine ( $650 \mathrm{mg}$ every $6-8 \mathrm{~h}$ orally) for $7-10$ days is the initial therapy that should be considered for patients with babesiosis. Clindamycin and quinine should be given for those with severe babesiosis [55].

Rickettsia species (the majority is represented by R. Helvetica and monacensis) is another agent of possible coinfection $[88,89]$. The clinical onset of rickettsiosis is characterized by fever and a small papule of $1-1.5 \mathrm{~cm}$ in diameter that developed in a small ulcer with a dark crust that leaves a scar when it heals. There is a regional lymphadenopathy. Then an intermittent fever, for a week, with chills, profuse sweating, headache, photophobia, and muscle aches. During the course of fever, generalized maculopapular rash appears early with intraepidermal vesicles, which spares the palms of hands and soles of the feet. The antibiotics of choice are tetracycline, doxycycline or chloramphenicol, at the doses used for other rickettsial exanthematous manifestations. Also ciprofloxacin and macrolides are active [90].

\subsection{Baggio-Yoshinary Syndrome}

Baggio-Yoshinary syndrome is a Brazilian zoonosis, a new tick borne disease caused by Borrelia spp, possibly a Borrelia burgdorferi sensu lato genetically modified or a new Borrelia species, transmitted by ticks of genus Amblyomma and Rhipicephalus [91, 92]. The first case was described in 1992 in Brazil, initially as a case resembling LD, then called Baggio-Yoshinary syndrome because of some epidemiological, clinical, and laboratory differences from LD [93, 94]. Clinically it mimics symptoms of LD but differs from it mainly for high frequencies of recurrent episodes and from the autoimmune component. In fact, patients suffering from Baggio-Yoshinary syndrome often present antinuclear antibodies, anti-cardiolipin antibodies, anti-neutrophil cytoplasmic antibodies and antineuronal antibodies [95]. The treatment of such a disease depends on the stage. Generally, in presence of neurological complications a therapy with ceftriaxone $2 \mathrm{~g}$ daily for 30 days followed by two or three months of doxycycline $100 \mathrm{mg}$ twice a day is recommended [93].

\section{CONCLUSION}

LD is a complex, multisystem and polymorphic illness that is easy to treat in most cases. Albeit its reference treatment is represented by antibiotics, currently there is no univocal consensus about the drug selection, route of administration, dose and duration of therapy for the various manifestations/stages of the disease. In general, the therapeutic outcome for LD seems quite favourable and similar among the different advised antibiotics, but about $10-20 \%$ of patients may show persistent or recurrent symptoms despite appropriate treatment. Large double-blind, controlled, long-term prospective trials are needed to assess the precise effectiveness and role of the various therapies and develop strategies for those patients not responding to the current treatment options.

\section{CONFLICT OF INTEREST}

The authors confirm that this article content has no conflict of interest.

\section{ACKNOWLEDGEMENTS}

Declared none. 


\section{REFERENCES}

[1] Vasudevan B, Chatterjee M. Lyme borreliosis and skin. Indian J Dermatol 2013; 58(3): 167-74. [http://dx.doi.org/10.4103/0019-5154.110822] [PMID: 23723463]

[2] Nau R, Christen H-J, Eiffert H. Lyme disease--current state of knowledge. Dtsch Arztebl Int 2009; 106(5): $72-81$. [PMID: 19562015]

[3] Biesiada G, Czepiel J, Leśniak MR, Garlicki A, Mach T. Lyme disease: review. Arch Med Sci 2012; 8(6): 978-82. [review]. [http://dx.doi.org/10.5114/aoms.2012.30948] [PMID: 23319969]

[4] Scarpa C, Trevisan G, Stinco G. Lyme borreliosis. Dermatol Clin 1994; 12(4): 669-85. [PMID: 7805296]

[5] Rizzoli A, Hauffe H, Carpi G, Vourc H G, Neteler M, Rosa R. Lyme borreliosis in Europe. Euro Surveill 2011; 16(27): 1-8. [PMID: 21794218]

[6] Clark KL, Leydet BF, Threlkeld C. Geographical and genospecies distribution of Borrelia burgdorferi sensu lato DNA detected in humans in the USA. J Med Microbiol 2014; 63(Pt 5): 674-84. [http://dx.doi.org/10.1099/jmm.0.073122-0] [PMID: 24568883]

[7] Rudenko N, Golovchenko M, Grubhoffer L, Oliver JH Jr. Updates on Borrelia burgdorferi sensu lato complex with respect to public health. Ticks Tick Borne Dis 2011; 2(3): 123-8. [http://dx.doi.org/10.1016/j.ttbdis.2011.04.002] [PMID: 21890064]

[8] Fukunaga M, Takahashi Y, Tsuruta Y, et al. Genetic and phenotypic analysis of Borrelia miyamotoi sp. nov., isolated from the ixodid tick Ixodes persulcatus, the vector for Lyme disease in Japan. Int J Syst Bacteriol 1995; 45(4): 804-10. [http://dx.doi.org/10.1099/00207713-45-4-804] [PMID: 7547303]

[9] Sarksyan DS, Platonov AE, Karan LS, et al. [Clinical presentation of "new" tick-borne borreliosis caused by Borrelia miyamotoi]. Ter Arkh 2012; 84(11): 34-41 [PMID: 23252245]

[10] Hansford KM, Fonville M, Jahfari S, Sprong H, Medlock JM. Borrelia miyamotoi in host-seeking Ixodes ricinus ticks in England. Epidemiol Infect 2014. [PMID: 25017971]

[11] Wormser GP, Dattwyler RJ, Shapiro ED, et al. The clinical assessment, treatment, and prevention of lyme disease, human granulocytic anaplasmosis, and babesiosis: clinical practice guidelines by the Infectious Diseases Society of America. Clin Infect Dis 2006; 43(9): 1089-134. [http://dx.doi.org/10.1086/508667] [PMID: 17029130]

[12] Shapiro ED. Clinical practice. Lyme disease. N Engl J Med 2014; 370(18): 1724-31. [http://dx.doi.org/10.1056/NEJMcp1314325] [PMID: 24785207]

[13] Lyme Disease - Treatment. Available from: http://www.cdc.gov/lyme/Treatment/ [Accessed 02 Feb 2015].

[14] Bhate C, Schwartz RA. Lyme disease: Part II. Management and prevention. J Am Acad Dermatol 2011; 64(4): 639-53. [http://dx.doi.org/10.1016/j.jaad.2010.03.047] [PMID: 21414494]

[15] Nadelman RB, Nowakowski J, Fish D, et al. Prophylaxis with single-dose doxycycline for the prevention of Lyme disease after an Ixodes scapularis tick bite. N Engl J Med 2001; 345(2): 79-84 [http://dx.doi.org/10.1056/NEJM200107123450201] [PMID: 11450675]

[16] Ticks - B. miyamotoi. Available from: http://www.cdc.gov/ticks/miyamotoi.html [Accessed 02 Feb 2015].

[17] Dattwyler RJ, Volkman DJ, Conaty SM, Platkin SP, Luft BJ. Amoxycillin plus probenecid versus doxycycline for treatment of erythema migrans borreliosis. Lancet 1990; 336(8728): 1404-6. [http://dx.doi.org/10.1016/0140-6736(90)93103-V] [PMID: 1978873]

[18] Massarotti EM, Luger SW, Rahn DW, et al. Treatment of early Lyme disease. Am J Med 1992; 92(4): 396-403. [http://dx.doi.org/10.1016/0002-9343(92)90270-L] [PMID: 1313637]

[19] Nadelman RB, Luger SW, Frank E, Wisniewski M, Collins JJ, Wormser GP. Comparison of cefuroxime axetil and doxycycline in the treatment of early Lyme disease. Ann Intern Med 1992; 117(4): 273-80. [http://dx.doi.org/10.7326/0003-4819-117-4-273] [PMID: 1637021]

[20] Luger SW, Paparone P, Wormser GP, et al. Comparison of cefuroxime axetil and doxycycline in treatment of patients with early Lyme disease associated with erythema migrans. Antimicrob Agents Chemother 1995; 39(3): 661-7. [http://dx.doi.org/10.1128/AAC.39.3.661] [PMID: 7793869]

[21] Eppes SC, Childs JA. Comparative study of cefuroxime axetil versus amoxicillin in children with early Lyme disease. Pediatrics 2002; 109(6): 1173-7. [http://dx.doi.org/10.1542/peds.109.6.1173] [PMID: 12042561]

[22] Luft BJ, Dattwyler RJ, Johnson RC, et al. Azithromycin compared with amoxicillin in the treatment of erythema migrans. A double-blind, randomized, controlled trial. Ann Intern Med 1996; 124(9): 785-91. [http://dx.doi.org/10.7326/0003-4819-124-9-199605010-00002] [PMID: 8610947] 
[23] Mygland A, Ljøstad U, Fingerle V, Rupprecht T, Schmutzhard E, Steiner I. EFNS guidelines on the diagnosis and management of European Lyme neuroborreliosis. Eur J Neurol 2010; 17(1): 8-16, e1-e4. [http://dx.doi.org/10.1111/j.1468-1331.2009.02862.x] [PMID: 19930447]

[24] Girschick HJ, Morbach H, Tappe D. Treatment of Lyme borreliosis. Arthritis Res Ther 2009; 11(6): 258. [http://dx.doi.org/10.1186/ar2853] [PMID: 20067594]

[25] Kohlhepp W, Oschmann P, Mertens HG. Treatment of Lyme borreliosis. Randomized comparison of doxycycline and penicillin G. J Neurol $1989 ; 236(8): 464-9$. [http://dx.doi.org/10.1007/BF00328508] [PMID: 2614491]

[26] Pfister HW, Preac-Mursic V, Wilske B, Einhäupl KM. Cefotaxime vs penicillin G for acute neurologic manifestations in Lyme borreliosis. A prospective randomized study. Arch Neurol 1989; 46(11): 1190-4. [http://dx.doi.org/10.1001/archneur.1989.00520470044025] [PMID: 2684107]

[27] Pfister HW, Preac-Mursic V, Wilske B, Schielke E, Sörgel F, Einhäupl KM. Randomized comparison of ceftriaxone and cefotaxime in Lyme neuroborreliosis. J Infect Dis 1991; 163(2): 311-8. [http://dx.doi.org/10.1093/infdis/163.2.311] [PMID: 1988514]

[28] Dattwyler RJ, Luft BJ, Kunkel MJ, et al. Ceftriaxone compared with doxycycline for the treatment of acute disseminated Lyme disease. N Engl J Med 1997; 337(5): 289-94. [http://dx.doi.org/10.1056/NEJM199707313370501] [PMID: 9233865]

[29] Borg R, Dotevall L, Hagberg L, et al. Intravenous ceftriaxone compared with oral doxycycline for the treatment of Lyme neuroborreliosis. Scand J Infect Dis 2005; 37(6-7): 449-54. [http://dx.doi.org/10.1080/00365540510027228] [PMID: 16012005]

[30] Karlsson M, Hammers-Berggren S, Lindquist L, Stiernstedt G, Svenungsson B. Comparison of intravenous penicillin G and oral doxycycline for treatment of Lyme neuroborreliosis. Neurology 1994; 44(7): 1203-7. [http://dx.doi.org/10.1212/WNL.44.7.1203] [PMID: 8035916]

[31] Ljøstad U, Skogvoll E, Eikeland R, et al. Oral doxycycline versus intravenous ceftriaxone for European Lyme neuroborreliosis: a multicentre, non-inferiority, double-blind, randomised trial. Lancet Neurol 2008; 7(8): 690-5. [http://dx.doi.org/10.1016/S1474-4422(08)70119-4] [PMID: 18567539]

[32] Thorstrand C, Belfrage E, Bennet R, Malmborg P, Eriksson M. Successful treatment of neuroborreliosis with ten day regimens. Pediatr Infect Dis J 2002; 21(12): 1142-5.

[http://dx.doi.org/10.1097/00006454-200212000-00011] [PMID: 12488665]

[33] Steere AC, Batsford WP, Weinberg M, et al. Lyme carditis: cardiac abnormalities of Lyme disease. Ann Intern Med 1980; 93(1): 8-16. [http://dx.doi.org/10.7326/0003-4819-93-1-8] [PMID: 6967274]

[34] Sigal LH. Early disseminated Lyme disease: cardiac manifestations. Am J Med 1995; 98(4A): 25S-8S. [http://dx.doi.org/10.1016/S0002-9343(99)80041-2] [PMID: 7726189]

[35] Pinto DS. Cardiac manifestations of Lyme disease. Med Clin North Am 2002; 86(2): 285-96. [http://dx.doi.org/10.1016/S0025-7125(03)00087-7] [PMID: 11982302]

[36] Strle F, Maraspin V, Pleterski-Rigler D, et al. Treatment of borrelial lymphocytoma. Infection 1996; 24(1): 80-4 [http://dx.doi.org/10.1007/BF01780665] [PMID: 8852477]

[37] Maraspin V, Cimperman J, Lotric-Furlan S, et al. Solitary borrelial lymphocytoma in adult patients. Wien Klin Wochenschr 2002; 114(13-14): 515-23 [PMID: 12422593]

[38] Treatment of Lyme borreliosis in Europe. Available from: http://www.eucalb.com/ [Accessed 09 Feb 2015]

[39] Eriksson P, Schröder MT, Niiranen K, Nevanlinna A, Panelius J, Ranki A. The many faces of solitary and multiple erythema migrans. Acta Derm Venereol 2013; 93(6): 693-700. [http://dx.doi.org/10.2340/00015555-1549] [PMID: 23450303]

[40] Wormser GP. Treatment and prevention of Lyme disease, with emphasis on antimicrobial therapy for neuroborreliosis and vaccination. Semin Neurol 1997; 17(1): 45-52. [http://dx.doi.org/10.1055/s-2008-1040912] [PMID: 9166959]

[41] Fishman RA. Blood-brain and CSF barriers to penicillin and related organic acids. Arch Neurol 1966; 15(2): 113-24. [http://dx.doi.org/10.1001/archneur.1966.00470140003001] [PMID: 5945968]

[42] Eckman MH, Steere AC, Kalish RA, Pauker SG. Cost effectiveness of oral as compared with intravenous antibiotic therapy for patients with early Lyme disease or Lyme arthritis. N Engl J Med 1997; 337(5): 357-63. [http://dx.doi.org/10.1056/NEJM199707313370525] [PMID: 9233874]

[43] Hassler D, Zöller L, Haude M, Hufnagel H-D, Heinrich F, Sonntag H-G. Cefotaxime versus penicillin in the late stage of Lyme disease-prospective, randomized therapeutic study. Infection 1990; 18(1): 16-20. [http://dx.doi.org/10.1007/BF01644175] [PMID: 2179134]

[44] Ettestad PJ, Campbell GL, Welbel SF, et al. Biliary complications in the treatment of unsubstantiated Lyme disease. J Infect Dis 1995; 
171(2): 356-61.

[http://dx.doi.org/10.1093/infdis/171.2.356] [PMID: 7844372]

[45] Dattwyler RJ, Halperin JJ, Volkman DJ, Luft BJ. Treatment of late Lyme borreliosis--randomised comparison of ceftriaxone and penicillin. Lancet 1988; 1(8596): 1191-4. [http://dx.doi.org/10.1016/S0140-6736(88)92011-9] [PMID: 2897008]

[46] Dattwyler RJ, Wormser GP, Rush TJ, et al. A comparison of two treatment regimens of ceftriaxone in late Lyme disease. Wien Klin Wochenschr 2005; 117(11-12): 393-7. [http://dx.doi.org/10.1007/s00508-005-0361-8] [PMID: 16053194]

[47] Dressler F, Girschick HJ, Huppertz HI, Lahdenne P. Pediatric Rheumatology European Society Clinical Guidelines: Lyme arthritis. Pediatr Rheumatol Online J 2004; 8: 346-9.

[48] Steere AC, Angelis SM. Therapy for Lyme arthritis: strategies for the treatment of antibiotic-refractory arthritis. Arthritis Rheum 2006; 54(10): 3079-86.

[http://dx.doi.org/10.1002/art.22131] [PMID: 17009226]

[49] Schoen RT, Aversa JM, Rahn DW, Steere AC. Treatment of refractory chronic Lyme arthritis with arthroscopic synovectomy. Arthritis Rheum 1991; 34(8): 1056-60. [http://dx.doi.org/10.1002/art.1780340817] [PMID: 1859481]

[50] Kindstrand E, Nilsson BY, Hovmark A, Pirskanen R, Asbrink E. Peripheral neuropathy in acrodermatitis chronica atrophicans - effect of treatment. Acta Neurol Scand 2002; 106(5): 253-7. [http://dx.doi.org/10.1034/j.1600-0404.2002.01336.x] [PMID: 12371917]

[51] Ogrinc K, Logar M, Lotric-Furlan S, Cerar D, Ruzić-Sabljić E, Strle F. Doxycycline versus ceftriaxone for the treatment of patients with chronic Lyme borreliosis. Wien Klin Wochenschr 2006; 118(21-22): 696-701. [http://dx.doi.org/10.1007/s00508-006-0698-7] [PMID: 17160610]

[52] Huppertz HI, Münchmeier D, Lieb W. Ocular manifestations in children and adolescents with Lyme arthritis. Br J Ophthalmol 1999; 83(10): 1149-52. [http://dx.doi.org/10.1136/bjo.83.10.1149] [PMID: 10502576]

[53] Suttorp-Schulten MS, Kuiper H, Kijlstra A, van Dam AP, Rothova A. Long-term effects of ceftriaxone treatment on intraocular Lyme borreliosis. Am J Ophthalmol 1993; 116(5): 571-5. [http://dx.doi.org/10.1016/S0002-9394(14)73198-8] [PMID: 8238216]

[54] Zaidman GW. The ocular manifestations of Lyme disease. Int Ophthalmol Clin 1997; 37(2): 13-28. [http://dx.doi.org/10.1097/00004397-199703720-00003] [PMID: 9269595]

[55] Müllegger RR, Glatz M. Skin manifestations of lyme borreliosis: diagnosis and management. Am J Clin Dermatol 2008; 9(6): 355-68. [http://dx.doi.org/10.2165/0128071-200809060-00002] [PMID: 18973402]

[56] Belum GR, Belum VR, Chaitanya Arudra SK, Reddy BS. The Jarisch-Herxheimer reaction: revisited. Travel Med Infect Dis 2013; 11(4): $231-7$. [http://dx.doi.org/10.1016/j.tmaid.2013.04.001] [PMID: 23632012]

[57] Schlesinger PA, Duray PH, Burke BA, Steere AC, Stillman MT. Maternal-fetal transmission of the Lyme disease spirochete, Borrelia burgdorferi. Ann Intern Med 1985; 103(1): 67-8. [http://dx.doi.org/10.7326/0003-4819-103-1-67] [PMID: 4003991]

[58] Walsh CA, Mayer EW, Baxi LV. Lyme disease in pregnancy: case report and review of the literature. Obstet Gynecol Surv 2007; 62(1): 41-50. [http://dx.doi.org/10.1097/01.ogx.0000251024.43400.9a] [PMID: 17176487]

[59] Gerber MA, Zalneraitis EL. Childhood neurologic disorders and Lyme disease during pregnancy. Pediatr Neurol 1994; 11(1): 41-3 [http://dx.doi.org/10.1016/0887-8994(94)90088-4] [PMID: 7986291]

[60] Maraspin V, Cimperman J, Lotric-Furlan S, Pleterski-Rigler D, Strle F. Treatment of erythema migrans in pregnancy. Clin Infect Dis 1996; 22(5): 788-93. [http://dx.doi.org/10.1093/clinids/22.5.788] [PMID: 8722932]

[61] Williams CL, Strobino B, Weinstein A, Spierling P, Medici F. Maternal Lyme disease and congenital malformations: a cord blood serosurvey in endemic and control areas. Paediatr Perinat Epidemiol 1995; 9(3): 320-30. [http://dx.doi.org/10.1111/j.1365-3016.1995.tb00148.x] [PMID: 7479280]

[62] Strobino BA, Williams CL, Abid S, Chalson R, Spierling P. Lyme disease and pregnancy outcome: a prospective study of two thousand prenatal patients. Am J Obstet Gynecol 1993; 169(2 Pt 1): 367-74. [http://dx.doi.org/10.1016/0002-9378(93)90088-Z] [PMID: 8362948]

[63] Post-Treatment Lyme Disease Syndrome. Available from: http://www.cdc.gov/lyme/postLDS/index.html [Accessed 10 Feb 2015].

[64] Feder HM Jr, Johnson BJ, O’Connell S, et al. A critical appraisal of “chronic Lyme disease”. N Engl J Med 2007; 357(14): 1422-30. [http://dx.doi.org/10.1056/NEJMra072023] [PMID: 17914043]

[65] Stricker RB, Johnson L. Lyme disease: the next decade. Infect Drug Resist 2011; 4: 1-9. [http://dx.doi.org/10.2147/IDR.S15653] [PMID: 21694904] 
[66] Deutsche Borreliose-Gesellschaft e.v. Diagnosis and Treatment of Lyme borreliosis- Guidelines. Available from: http://www.borreliosegesellschaft.de/Texte/guidelines.pdf [Accessed 10 Feb 2015].

[67] Halperin JJ. Nervous system lyme disease: diagnosis and treatment. Rev Neurol Dis 2009; 6(1): 4-12. [PMID: 19367218]

[68] Klempner MS, Hu LT, Evans J, et al. Two controlled trials of antibiotic treatment in patients with persistent symptoms and a history of Lyme disease. N Engl J Med 2001; 345(2): 85-92.

[http://dx.doi.org/10.1056/NEJM200107123450202] [PMID: 11450676]

[69] Trevisan G, Rees DH, Stinco G. Borrelia burgdorferi and localized scleroderma. Clin Dermatol 1994; $12(3)$ : $475-9$. [http://dx.doi.org/10.1016/0738-081X(94)90300-X] [PMID: 7954205]

[70] Trevisan G, Menni S, Stinco G, et al. Lichen slerosus et atrophicus and Borrelia burgdorferi infection. Eur J Pediat Dermatol 1994; 4: 159-62.

[71] Trevisan G, Stinco G, Nobile C, Bonin S, Stanta G. Detection of Borrelia burgdorferi in skin biopsies from patients with morphea by polymerase chain reaction. J Eur Acad Dermatol Venereol 1996; 6: 15-9. [http://dx.doi.org/10.1111/j.1468-3083.1996.tb00127.x]

[72] Gubertini N, Bonin S, Trevisan G. Lichen sclerosus et atrophicans, scleroderma en coup de sabre and Lyme borreliosis. Dermatol Rep 2011; 3(2): e27.

[http://dx.doi.org/10.4081/dr.2011.e27] [PMID: 25386279]

[73] Trevisan G, Padovan C, Scaini MT, Cinco M, Floris R, Bonin S. Anetoderma associated with lyme disease: a case report. Acta Derm Venereol 2008; 88(5): 536-8. [http://dx.doi.org/10.2340/00015555-0513] [PMID: 18779908]

[74] Stinco G, Ruscio M, Proscia D, Piccirillo F. Borrelia infection and pityriasis rosea. Acta Derm Venereol 2009; 89(1): 97-8. [http://dx.doi.org/10.2340/00015555-0544] [PMID: 19197556]

[75] Menni S, Pistritto G, Gelmetti C, Stanta G, Trevisan G. Pityriasis lichenoide-like lesions with perifolliculitis in Lyme borreliosis. Eur J Pediat Dermatol 1994; 4: 77-80.

[76] Stinco G, Ruscio M, Bergamo S, Trotter D, Patrone P. Clinical features of 705 Borrelia burgdorferi seropositive patients in an endemic area of northern Italy. Scientific World Journal 2014; 2014: 414505.

[77] Schöllkopf C, Melbye M, Munksgaard L, et al. Borrelia infection and risk of non-Hodgkin lymphoma. Blood 2008; 111(12): 5524-9. [http://dx.doi.org/10.1182/blood-2007-08-109611] [PMID: 18424667]

[78] Kütting B, Bonsmann G, Metze D, Luger TA, Cerroni L. Borrelia burgdorferi-associated primary cutaneous B cell lymphoma: complete clearing of skin lesions after antibiotic pulse therapy or intralesional injection of interferon alfa-2a. J Am Acad Dermatol 1997; 36(2 Pt 2): $311-4$. [http://dx.doi.org/10.1016/S0190-9622(97)80405-7] [PMID: 9039207]

[79] Gatti A, Stinco G, Trevisini S, et al. Electrochemotherapy as a novel treatment for primary cutaneous marginal zone B-cell lymphomas. Dermatol Ther (Heidelb) 2014; 27(4): 244-7 [http://dx.doi.org/10.1111/dth.12128] [PMID: 24754311]

[80] Trevisan G. Atypical dermatological manifestations of Lyme borreliosis. Acta Dermovenereologica APA 2001; 10 : 149-51.

[81] Lee Y, Oh Y, Ahn SY, Park HY, Choi EH. A case of atrophoderma of Pasini and Pierini associated with Borrelia burgdorferi infection successfully treated with oral doxycycline. Ann Dermatol 2011; 23(3): 352-6. [http://dx.doi.org/10.5021/ad.2011.23.3.352] [PMID: 21909207]

[82] Stinco G. Lyme disease, atypical skin manifestations. Acta Dermatovenereologica APA 1994; 3: 49-52.

[83] Lantos PM, Wormser GP. Chronic coinfections in patients diagnosed with chronic lyme disease: a systematic review. Am J Med 2014; 127(11): 1105-10.

[http://dx.doi.org/10.1016/j.amjmed.2014.05.036] [PMID: 24929022]

[84] Mayne PJ. Clinical determinants of Lyme borreliosis, babesiosis, bartonellosis, anaplasmosis, and ehrlichiosis in an Australian cohort. Int J Gen Med 2015; 8: 15-26. [PMID: 25565883]

[85] Hersh MH, Ostfeld RS, McHenry DJ, et al. Co-infection of blacklegged ticks with Babesia microti and Borrelia burgdorferi is higher than expected and acquired from small mammal hosts. PLoS One 2014; 9(6): e99348. [http://dx.doi.org/10.1371/journal.pone.0099348] [PMID: 24940999]

[86] Dunn JM, Krause PJ, Davis S, et al. Borrelia burgdorferi promotes the establishment of Babesia microti in the northeastern United States. PLoS One 2014; 9(12): e115494. [http://dx.doi.org/10.1371/journal.pone.0115494] [PMID: 25545393]

[87] Zhou X, Xia S, Huang JL, Tambo E, Zhuge HX, Zhou XN. Human babesiosis, an emerging tick-borne disease in the People's Republic of China. Parasit Vectors 2014; 7: 509 [PMID: 25403908]

[88] Benredjem W, Leulmi H, Bitam I, Raoult D, Parola P. Borrelia garinii and Rickettsia monacensis in Ixodes ricinus ticks, Algeria. Emerg Infect Dis 2014; 20(10): 1776-7. 
[http://dx.doi.org/10.3201/eid2010.140265] [PMID: 25272139]

[89] Bitam I, Raoult D. Other tick-borne diseases in Europe. Curr Probl Dermatol 2009; 37: 130-54. [http://dx.doi.org/10.1159/000213072] [PMID: 19367099]

[90] Tijsse-Klasen E, Sprong H, Pandak N. Co-infection of Borrelia burgdorferi sensu lato and Rickettsia species in ticks and in an erythema migrans patient. Parasit Vectors 2013; 6: 347. [http://dx.doi.org/10.1186/1756-3305-6-347] [PMID: 24326096]

[91] Kowacs PA, Martins RT, Piovesan EJ, Pinto MC, Yoshinari NH. Chronic unremitting headache associated with Lyme disease-like illness. Arq Neuropsiquiatr 2013; 71(7): 470-3.

[http://dx.doi.org/10.1590/0004-282X20130064] [PMID: 23857618]

[92] Montandon CE, Yoshinari NH, Milagres BS, et al. Evidence of Borrelia in wild and domestic mammals from the state of Minas Gerais, Brazil. Rev Bras Parasitol Vet 2014; 23(2): 287-90. [http://dx.doi.org/10.1590/S1984-29612014040] [PMID: 25054516]

[93] Yoshinari NH, Mantovani E, Bonoldi VL, Marangoni RG, Gauditano G. [Brazilian lyme-like disease or Baggio-Yoshinari syndrome: exotic and emerging Brazilian tick-borne zoonosis]. Rev Assoc Med Bras 2010; 56(3): 363-9. [http://dx.doi.org/10.1590/S0104-42302010000300025] [PMID: 20676548]

[94] Oliveira Ad, Fonseca AH, Costa CM, Mantovani E, Yoshinari NH. Growth, cysts and kinetics of Borrelia garinii (Spirochaetales: Spirochaetacea) in different culture media. Mem Inst Oswaldo Cruz 2010; 105(5): 717-9. [http://dx.doi.org/10.1590/S0074-02762010000500020] [PMID: 20835623]

[95] Gouveia EA, Alves MF, Mantovani E, Oyafuso LK, Bonoldi VL, Yoshinari NH. Profile of patients with Baggio-Yoshinari Syndrome admitted at "Instituto de Infectologia Emilio Ribas". Rev Inst Med Trop Sao Paulo 2010; 52(6): 297-303. [PMID: 21225212]

Received: October 22, 2015 Revised: December 16, 2015 Accepted: December 16, 2015

(C) Trevisan et al.; Licensee Bentham Open.

This is an open access article licensed under the terms of the Creative Commons Attribution-Non-Commercial 4.0 International Public License (CC BY-NC 4.0) (https://creativecommons.org/licenses/by-nc/4.0/legalcode), which permits unrestricted, non-commercial use, distribution and reproduction in any medium, provided the work is properly cited. 